\title{
High compliance to ERAS protocol does not improve overall survival in patients treated for resectable advanced gastric cancer
}

\author{
Mateusz Rubinkiewicz ${ }^{1}$, Magdalena Pisarska ${ }^{1}$, Piotr Zarzycki ${ }^{1}$, Katarzyna Truszkiewicz ${ }^{1}$, Jan Witowski ${ }^{1}$, Michael Su$^{2}$, \\ Robert Kupis², Anna Gajdosz², Michał Pędziwiatr ${ }^{1}$ \\ ${ }^{1} 2^{\text {nd }}$ Department of General Surgery, Jagiellonian University Medical College, Krakow, Poland \\ ${ }^{2}$ Faculty of Medicine, Jagiellonian University Medical College, Krakow, Poland
}

Videosurgery Miniinv 2020; 15 (4): 553-559

DOI: https://doi.org/10.5114/wiitm.2020.92833

\begin{abstract}
Introduction: The ERAS (Enhanced Recovery after Surgery) protocol revolutionized perioperative care for gastrointestinal surgical procedures. However, little is known about the association between adherence to the ERAS protocol in gastric cancer surgery and the oncological outcome.

Aim: To explore the relation between adherence to the ERAS protocol and the oncological outcome in gastric cancer patients.

Material and methods: We performed a retrospective analysis of a prospectively collected database of patients treated for gastric cancer between 2013 and 2016. All patients were treated perioperatively with a 14-item ERAS protocol. Every patient underwent regular follow-up every 3 months for 3 years after surgery. $80 \%$ compliance to the ERAS protocol was the goal during perioperative care. Based on the level of compliance, patients were divided into group 1 and group 2 (compliance of $\geq 80 \%$ and $<80 \%$, respectively).

Results: Compliance to the ERAS protocol was not a risk factor for diminished overall survival - probability of 3-year survival was $63 \%$ in group 1 and $56 \%$ in group $2(p=0.75)$. The proportional Cox model revealed that only stage III gastric cancer was a risk factor of poor prognosis in patients operated on for gastric cancer ( $H R=7.89,95 \% \mathrm{Cl}$ : 2.96-20.89; $p=0.0001$ ).

Conclusions: High adherence to the ERAS protocol did not improve overall survival in our 3-year observation. Only the stage of the disease, according to the AJCC classification, was identified as a risk factor for poor prognosis.
\end{abstract}

Key words: enhanced recovery after surgery, gastric cancer, gastrectomy, laparoscopy, adherence.

\section{Introduction}

Minimally invasive surgery and the ERAS (Enhanced Recovery after Surgery) protocol revolutionized perioperative care for gastrointestinal surgical procedures [1-4]. While the most extensive research involved colorectal diseases, ERAS was found to be beneficial in other branches of surgery $[5,6]$. Its ap- plication diminished postoperative morbidity and reduced hospital length of stay [6]. In 2014 the ERAS Society published its guidelines for perioperative care after gastrectomy [7]. Many versions of the ERAS protocol, however, are still being used in different surgical departments $[6,8]$. Nevertheless, the main elements of the ERAS protocol remain common [6]. Many authors report that introduction of the 
ERAS protocol improves the short-term outcomes as well as compliance to its elements [9]. However, the ERAS protocol is not as commonly used in gastric surgery. Studies on long-term outcomes in this field are lacking, too [10]. The advances in surgical technique currently are marginal; therefore we should investigate meticulously other items contributing to final outcomes of gastric cancer surgery [11]. Recently, several papers revealed that compliance to the ERAS protocol may affect long-term survival in patients with cancer $[12,13]$, which is the most objective benchmark in assessment of oncological treatment. The reason for this association is still under investigation. So far, no such influence has been investigated regarding gastric cancer surgery.

\section{Aim}

To evaluate whether adherence to the ERAS protocol affects survival in patients undergoing gastric cancer surgery.

Table I. ERAS protocol used in our department

\begin{tabular}{|c|}
\hline 1. Preoperative counseling and patient's education \\
\hline $\begin{array}{l}\text { 2. Pre-operative carbohydrate loading ( } 400 \mathrm{ml} \text { of Nutricia } \\
\text { preOp } 2 \mathrm{~h} \text { prior to surgery) }\end{array}$ \\
\hline $\begin{array}{l}\text { 3. Antithrombotic prophylaxis (Clexane } 40 \mathrm{mg} \text { s.c. starting } \\
\text { in the evening prior to surgery) }\end{array}$ \\
\hline $\begin{array}{l}\text { 4. Antibiotic prophylaxis (preoperative ceftriaxone } 2 \mathrm{~g} \text { i.v. } \\
30-60 \text { min prior surgery) }\end{array}$ \\
\hline 5. Laparoscopic surgery \\
\hline $\begin{array}{l}\text { 6. Balanced intravenous fluid therapy }(<2500 \mathrm{ml} \text { of intra- } \\
\text { venous fluids during the day of surgery, less than } \\
150 \mathrm{mmol} \text { sodium })\end{array}$ \\
\hline 7. No nasogastric tubes postoperatively \\
\hline 8. No drains left routinely \\
\hline 9. TAP block and standard anesthesia protocol \\
\hline $\begin{array}{l}\text { 10. Avoiding opioids, multimodal analgesia (oral when } \\
\text { possible - paracetamol } 4 \times 1 \text { g, ibuprofen } 2 \times 200 \mathrm{mg} \text {, } \\
\text { metamizole } 2 \times 500 \mathrm{mg} \text {, or ketoprofen } 2 \times 100 \mathrm{mg} \text { ) }\end{array}$ \\
\hline 11. Postoperative oxygenation therapy (4-6 l/min) \\
\hline $\begin{array}{l}\text { 12. Early oral feeding (oral nutritional supplement } 4 \mathrm{~h} \text { post- } \\
\text { operatively - Nutricia Nutridrink or Nestlé Impact, light } \\
\text { hospital diet and oral nutritional supplements on the } \\
\text { first postoperative day, full hospital diet on the second } \\
\text { postoperative day) }\end{array}$ \\
\hline 13. Urinary catheter removal on the first postoperative day \\
\hline $\begin{array}{l}\text { 14. Full mobilization on the first postoperative day (getting } \\
\text { out of bed, going to toilette, walking along the corridor, } \\
\text { at least } 4 \mathrm{~h} \text { out of bed) }\end{array}$ \\
\hline
\end{tabular}

\section{Material and methods}

We performed a retrospective analysis of a prospective collected database of patients treated for gastric cancer between 2013 and 2016. In 2012 laparoscopic total gastrectomy became the method of choice in gastric cancer. Qualification for preoperative chemotherapy was performed based on ESMO guidelines [14]. All patients were treated perioperatively with a 14-item ERAS protocol (Table I).

Every patient underwent regular follow-up every 3 months for 3 years after surgery. It included general check-up and computed tomography imaging for recurrence and distant metastasis evaluation.

\section{Operative technique}

All patients underwent D2 gastrectomy with spleen preservation in the laparoscopic approach. Reconstruction of the digestive tract was done with the Roux-en-Y approach. The esophago-jejunal anastomosis was carried out with a linear $45 \mathrm{~mm}$ GIA stapler and jejuno-jejunal anastomosis. In both anastomoses the common orifice was closed by a hand-sewn suture. No routine drainage of the peritoneal cavity was used.

\section{Inclusion criteria}

Inclusion criteria were: 18 years old, histologically confirmed gastric adenocarcinoma, procedure performed with a laparoscopic approach (gastrectomy with D2 lymphadenectomy), and follow-up of at least 12 months. Patients with stage IV cancer according to the AJCC classification, patients operated initially with an open approach and patients after conversion, patients who died within 30 days after the initial procedure, and patients requiring multivisceral resections and patients with locally inoperable cancer were all excluded from the analysis.

\section{Outcome measures}

For the study purposes, patients were divided into two groups depending on their compliance to the ERAS protocol. Patients with compliance of equal to or more than $80 \%$ formed group 1 . Patients with compliance of less than $80 \%$ represented group 2 . We did not include postoperative elements of the ERAS protocol in the adherence calculation. As a result, compliance to the ERAS protocol was calculated by dividing the number of components fulfilled by 11 . 
The primary outcome was 3-year overall survival. The secondary outcomes were perioperative complications, length of stay, and recovery parameters.

\section{Ethical approval}

The study was approved by the local Ethics Review Committee (approval number 1072.6120.225.2017). All procedures were performed in accordance with the ethical standards laid down in the 1964 Declaration of Helsinki and its later amendments.

\section{Statistical analysis}

All data were analyzed with StatSoft Statistica v.13 (StatSoft Inc., Tulsa, OK, USA). The results are presented as mean \pm standard deviation (SD), median and interquartile range (IQR), and hazard ratio $(\mathrm{HR})$ with $95 \%$ confidence intervals $(\mathrm{Cl})$ when appropriate. The study of categorical variables used the $\chi^{2}$ test of independence. The Shapiro-Wilk test was used to check for normal distribution of data and Student's test was used for normally distributed quantitative data. For non-normally distributed quantitative variables, the Mann-Whitney $U$ test was used. For the purposes of further analysis, the entire group of patients was divided into subgroups depending on compliance with the ERAS protocol ( $<80 \%$ and $\geq 80 \%)$. This was the target compliance with the ERAS protocol in our department. Survival data were analyzed according to the Kaplan-Meier method. The log-rank test was used to detect differences between groups. Univariate and multivariate analysis was performed using Cox proportional hazards. The variables with $p<0.05$ were included in the model. Results were considered statistically significant when the $p$-value was found to be less than 0.05 .

\section{Results}

During the study period, 97 patients with gastric cancer underwent total gastrectomy. Eventually, 78 patients were included in the analysis (51 males and 27 females). Mean age was $61.2 \pm 10.7$ years. Mean compliance to the ERAS protocol in the whole group was $75.6 \%$.

Group 1 (patients with compliance > 80\%) included 34 patients and group 2 (patients with compliance < 80\%) included 44 patients. The groups did not differ in terms of sex, age, BMI, ASA class and comorbidities. Both groups were also similar in terms of stage of the disease. Forty-six (58\%) patients required adjuvant chemotherapy; the number of individuals was not statistically different between groups. The data are summarized in Table II.

A subgroup analysis demonstrated that the patients in group 1 and group 2 did not statistically differ in terms of 3-year overall survival (Figure 1).

Patients in group 1 required shorter length of stay in the hospital (mean: $6.0 \pm 4.1$ days vs. 10.4 \pm 13.3 days; $p=0.0052$ ). However, multivariate regression analysis revealed that only complications were a risk factor for prolonged hospitalization ( $\beta=$ $-0.68 ; 95 \% \mathrm{Cl}:(-0.95,-0.42) ; p<0.001)$. Patients with high compliance had a lower complication rate (20.6\% vs. $29.5 \%$ ), although the result did not reach statistical significance.

Univariate analysis of overall survival identified only stage III AJCC as a risk factor of poor prognosis in patients operated on due to gastric cancer $(\mathrm{HR}=$ 7.89, 95\% Cl: 2.96-20.89; $p=0.0001$; Table III).

According to Kaplan-Maier curves, probability of 3 -year overall survival for group 1 was $63 \%$ and $56 \%$ (12/44) for group 2 (Figure 2). These two groups did not differ statistically significantly $(p=0.75)$.

Kaplan-Maier curves show decreased probability of overall survival in patients with stage III AJCC, which is 28 in 3-year observation (Figure 3). In patients with stage I and II overall survival was $87 \%$ $(p<0.001)$.

We also analyzed the influence of complications on overall survival. There were no statistically significant differences between groups of patients with no complications, patients with Clavien-Dindo I-II complications and patients with Clavien-Dindo III-IV complications $(p=0.22)$.

\section{Discussion}

Our study showed that compliance to the ERAS protocol positively impacts short-term outcomes, but it does not influence 3-year survival. The only factor that worsens the patient's prognosis is the stage of the disease. This is to our best knowledge the first study investigating this problem.

Compliance to ERAS seems not to influence patient survival. Our findings are contrary to Gustafsson et al., who observed improved long-term outcomes in colorectal cancer surgery in patients with high compliance to the ERAS protocol [12]. Pisarska 
Table II. Demographic analysis of patient group

\begin{tabular}{|c|c|c|c|c|}
\hline Parameter & Total & Group 1 & Group 2 & $P$-value \\
\hline Number of patients, $n$ & 78 & 34 & 44 & - \\
\hline Females, $n(\%)$ & $27(34.6)$ & $10(29.4)$ & $17(38.6)$ & \multirow[t]{2}{*}{0.3939} \\
\hline Males, $n(\%)$ & $51(65.4)$ & $24(70.6)$ & $27(61.4)$ & \\
\hline Age, mean \pm SD [years] & $61.2 \pm 10.7$ & $61.1 \pm 10.3$ & $61.3 \pm 11.2$ & 0.9466 \\
\hline $\mathrm{BMI}, \mathrm{mean} \pm \mathrm{SD}\left[\mathrm{kg} / \mathrm{m}^{2}\right]$ & $25.7 \pm 4.1$ & $25.5 \pm 3.7$ & $25.9 \pm 4.4$ & 0.7772 \\
\hline ASA $1, n(\%)$ & $1(1.3)$ & $1(2.9)$ & - & \multirow[t]{4}{*}{0.5581} \\
\hline ASA $2, n(\%)$ & $62(79.5)$ & $27(79.4)$ & $35(79.5)$ & \\
\hline ASA $3, n(\%)$ & $14(17.9)$ & $6(17.6)$ & $8(18.2)$ & \\
\hline ASA $4, n(\%)$ & $1(1.3)$ & - & $1(2.3)$ & \\
\hline Any comorbidity, $n$ (\%) & $53(67.9)$ & $26(76.5)$ & $27(61.4)$ & 0.1525 \\
\hline Cardiovascular, n (\%) & $19(24.4)$ & $8(23.5)$ & $11(25)$ & 0.8806 \\
\hline Hypertension, n (\%) & $28(35.9)$ & $11(32.4)$ & $17(38.6)$ & 0.5654 \\
\hline Diabetes, $n$ (\%) & $9(11.5)$ & $2(5.9)$ & $7(15.9)$ & 0.1553 \\
\hline Liver disease, $n(\%)$ & $5(6.4)$ & $1(2.9)$ & $1(2.3)$ & 0.8536 \\
\hline Operative time, median (IQR) [min] & $307.4 \pm 90.9$ & $275(242-332)$ & $300(240-355)$ & 0.6511 \\
\hline Intraoperative blood loss, median (IQR) [ml] & $317 \pm 272.6$ & $200(200-300)$ & $200(150-500)$ & 0.4491 \\
\hline Conversion, $n(\%)$ & $3(3.8)$ & $1(2.9)$ & $2(4.5)$ & 0.7149 \\
\hline Neoadjuvant treatment, $n(\%)$ & $53(67.9)$ & $24(70.6)$ & $29(65.9)$ & 0.6599 \\
\hline Adjuvant treatment, $n(\%)$ & $46(59)$ & $19(56)$ & $27(61)$ & 0.8037 \\
\hline AJCC Stage $0, n(\%)$ & $5(6.4)$ & $2(5.9)$ & $3(6.8)$ & \multirow[t]{4}{*}{0.7004} \\
\hline AJCC Stage I, $n(\%)$ & $22(28.2)$ & $11(32.4)$ & $9(20.5)$ & \\
\hline AJCC Stage II, $n$ (\%) & $20(25.6)$ & $7(20.6)$ & $11(25)$ & \\
\hline AJCC Stage III, $n(\%)$ & $31(39.7)$ & $14(41.2)$ & $21(47.7)$ & \\
\hline Tumor grade G1, $n$ (\%) & $1(1.3)$ & - & $1(2.3)$ & \multirow[t]{3}{*}{0.5329} \\
\hline Tumor grade G2, $n$ (\%) & $46(59.0)$ & $21(61.8)$ & $25(56.8)$ & \\
\hline Tumor grade G3, $n$ (\%) & $31(39.7)$ & $13(38.2)$ & $18(40.9)$ & \\
\hline Time to first flatus, mean \pm SD [days] & $2.6 \pm 1.2$ & $2.6 \pm 0.9$ & $2.6 \pm 1.4$ & 0.9874 \\
\hline Patients without complications, $n(\%)$ & $58(74.4)$ & $27(79.4)$ & $31(70.7)$ & \multirow[t]{2}{*}{0.3656} \\
\hline Patients with complications, $n$ (\%) & $20(25.6)$ & $7(20.6)$ & $13(29.5)$ & \\
\hline Clavien-Dindo 1, n (\%) & 3 & $2(5.9)$ & $1(.2 .3)$ & \multirow[t]{4}{*}{0.4358} \\
\hline Clavien-Dindo $2, n(\%)$ & $6(7.7)$ & $1(2.9)$ & $5(11.4)$ & \\
\hline Clavien-Dindo $3, n(\%)$ & $7(9.0)$ & $2(5.9)$ & $5(11.4)$ & \\
\hline Clavien-Dindo 4, n (\%) & $3(3.8)$ & $1(2.9)$ & $2(4.5)$ & \\
\hline Length of hospital stay, mean \pm SD [days] & $8.3 \pm 10.1$ & $6.0 \pm 4.1$ & $10.4 \pm 13.3$ & \multirow[t]{2}{*}{0.0052} \\
\hline Length of hospital stay, median (IQR) [days] & $6(4-8)$ & $5(4-6)$ & $7(5-8)$ & \\
\hline Readmission, $n$ (\%) & $11(14.1)$ & $6(17.6)$ & $5(11.4)$ & 0.4319 \\
\hline
\end{tabular}




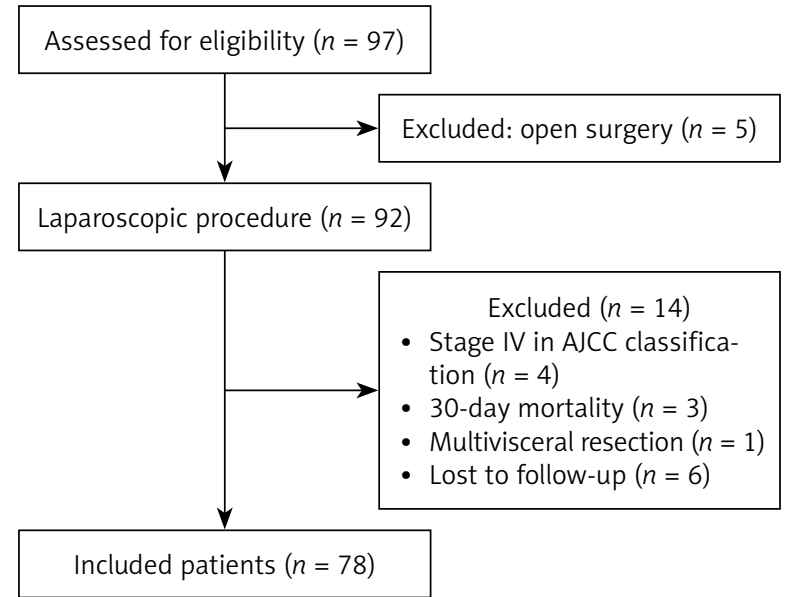

Figure 1. Patients flow through the study

et al. also found benefit of adherence to the ERAS protocol, observing better overall survival in patients with at least $80 \%$ compliance [13]. However, it is not easy to explain the why ERAS could possibly improve oncological outcomes. Asklid et al. reported that balanced fluid therapy in the perioperative course also could improve 5-year survival [15]. The topic is still under investigation, and it is highly likely that better survival is a consequence of many marginal gains in the perioperative period.

The ERAS protocol improves short-term outcomes, diminishing the rate of postoperative complications [16-18]. Some authors suggest that complications may negatively impact long-term survival [19]. Wang et al. performed a meta-analysis in which they found that postoperative complications

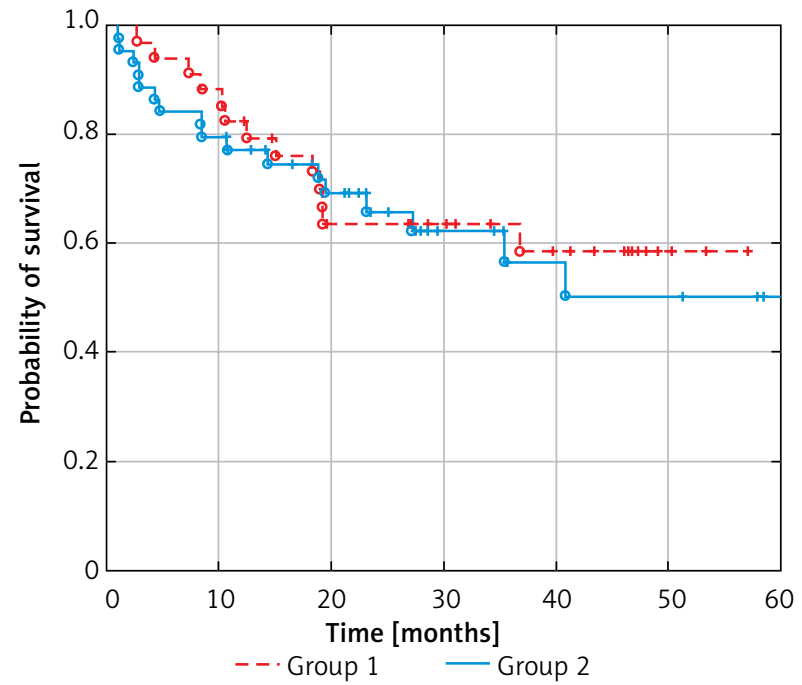

Figure 2. Kaplan-Meier survival estimates according to ERAS protocol adherence
Table III. Univariate analysis of overall survival

\begin{tabular}{|c|c|c|}
\hline Parameter & $\mathrm{HR}(95 \% \mathrm{Cl})$ & $P$-value \\
\hline Sex (female vs. male) & $1.13(0.52-2.48)$ & 0.7534 \\
\hline Age (< 65 vs. $\geq 65$ years) & $1.01(0.47-2.16)$ & 0.9781 \\
\hline $\mathrm{BMI}\left(<25 \mathrm{vs} . \geq 25 \mathrm{~kg} / \mathrm{m}^{2}\right)$ & $0.49(0.22-1.07)$ & 0.0729 \\
\hline ASA scale (I-II vs. III-IV) & $1.42(0.61-3.37)$ & 0.4229 \\
\hline $\begin{array}{l}\text { Neoadjuvant treatment } \\
\text { (yes vs. no) }\end{array}$ & $1.09(0.49-2.45)$ & 0.8255 \\
\hline $\begin{array}{l}\text { Cardiovascular disease } \\
\text { (no vs. yes) }\end{array}$ & $1.35(0.59-3.09)$ & 0.4812 \\
\hline Hypertension (no vs. yes) & $0.88(0.40-1.97)$ & 0.7659 \\
\hline Diabetes (no vs. yes) & $0.77(0.18-3.28)$ & 0.7283 \\
\hline Liver disease (no vs. yes) & $1.02(0.58-1.28)$ & 0.4334 \\
\hline Renal disease (no vs. yes) & $1.27(0.46-1.72)$ & 0.7318 \\
\hline $\begin{array}{l}\text { Adherence to ERAS } \\
(<80 \%)\end{array}$ & $0.83(0.37-1.85)$ & 0.6620 \\
\hline AJCC (I-II vs. III) & $7.87(2.96-20.89)$ & $<0.0001$ \\
\hline Adjuvant chemotherapy & $2.5(0.51-12,32)$ & 0.2500 \\
\hline $\begin{array}{l}\text { Duration of the surgery } \\
(<300 \text { vs. }>300 \mathrm{~min})\end{array}$ & $0.81(0.38-1.71)$ & 0.5715 \\
\hline $\begin{array}{l}\text { Intraoperative blood loss } \\
(<200 \text { vs. }>200 \mathrm{ml})\end{array}$ & $1.58(0.21-2.02)$ & 0.6113 \\
\hline $\begin{array}{l}\text { Postoperative complica- } \\
\text { tions (no vs. yes) }\end{array}$ & $1.79(0.79-3.99)$ & 0.1571 \\
\hline
\end{tabular}

correlate with poor survival in patients with stage II and III of the disease [20]. However, in patients with stage I complications it had no impact on the

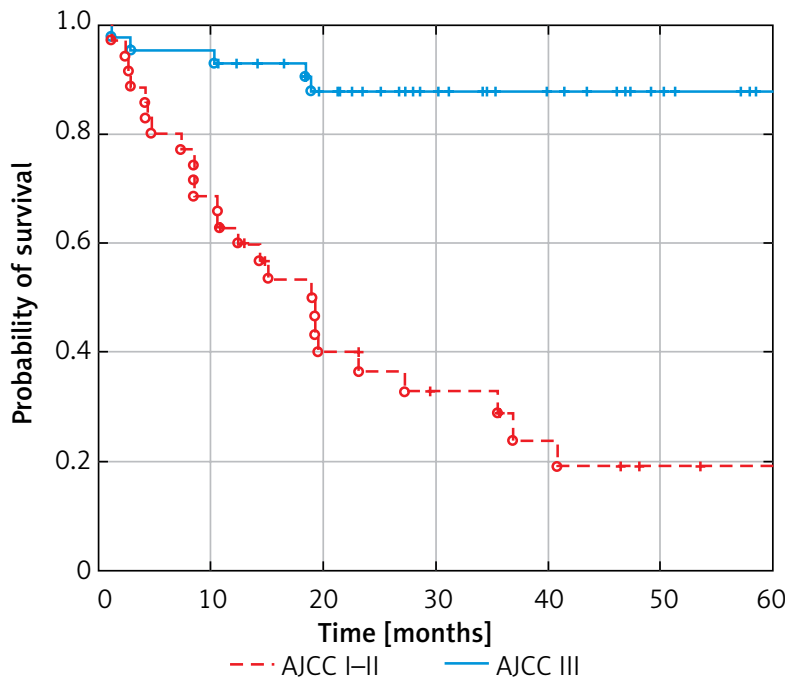

Figure 3. Kaplan-Meier survival estimates according to stage of the disease 
oncological outcomes [20]. On the other hand, Climent reported the following risk factors for worse survival: male gender, stage III of the disease and D1 lymphadenectomy; complications however were not associated with worse long-term prognosis [21]. In our study, only stage III cancer was a risk factor for poor survival. However, we did not assess the type of lymphadenectomy, because D2 lymphadenectomy in our unit is performed routinely.

Patients with high compliance had a significant shorter length of stay in comparison to those with low compliance. This result are in line with many other studies, as shortening of LOS is one of the main benefits of the ERAS protocol reported in the literature. Li et al. in their meta-analysis of 6 randomized control trials confirmed the benefit also for patients undergoing gastrectomy for gastric cancer [22].

What is important is that the ERAS protocol has many different modifications. Implemented protocols vary, including between 12 and 25 elements [23-25]. In our department we use a 14-element protocol for gastric cancer, and 16 elements for colorectal procedures $[13,26]$. However, most of the elements are common for all ERAS protocols.

In our study we decided not to include postoperative elements in ERAS adherence calculation. Also, in our high compliance group, we observed a significantly shorter length of hospital stay. Moreover, we observed fewer Clavien-Dindo II-IV complications in the high compliance group, although the data did not reach statistical significance. On the other hand, Aarts et al. found that postoperative components have the strongest impact on overall result [27]. Having said that, they still underline the significance of preoperative elements. Kehlet also stresses that core elements of ERAS improve the final outcomes [28]. We focused on pre- and intraoperative elements of ERAS, because they are mostly staff-dependent. Moreover, these elements influence the compliance with postoperative elements, which in this situation could be regarded as an outcome. It is also worth remembering that not only perioperative care but also proper surgical technique with D2 lymphadenectomy and neoadjuvant treatment are the basis of a good final outcome.

There are some limitations of our study. Firstly, our sample size is fairly small and some subgroups might be underpowered for adequate statistical analysis, especially in patients with Clavien-Dindo grade III and IV complications. Secondly, we also used the national personal identification number database to gather data on overall survival, which allows us to access only date of death but not information whether the death was cancer-specific. Next, the impact of the learning curve of laparoscopic gastrectomy has to be taken into consideration due to the complexity of the procedure requiring a significant number of cases for proficiency [29]. That could be a possible source of bias in the early stages of the study. Finally, we do not have complete information about adjuvant therapy, since some of our patients chose the treatment in other oncological centers.

\section{Conclusions}

High adherence ( $80 \%$ and higher) to the ERAS protocol does not improve overall survival in our 3-year observation. Only the stage of the disease according to the AJCC classification was identified as a risk factor for poor prognosis.

\section{Conflict of interest}

The authors declare no conflict of interest.

\section{References}

1. Major P, Wysocki M, Pędziwiatr M, et al. More stapler firings increase the risk of perioperative morbidity after laparoscopic sleeve gastrectomy. Videosurgery Miniinv 2018; 13: 88-94.

2. Kisialeuski M, Pędziwiatr M, Matłok $M$, et al. Enhanced recovery after colorectal surgery in elderly patients. Videosurgery Miniinv 2015; 10: 30-6.

3. Rubinkiewicz M, Migaczewski M, Hankus J, et al. The number of regulatory Foxp3+ T-cells in different stages of malignant transformation of large intestinal polyps. Adv Med Sci 2016; 61: 306-10.

4. Piątkowski J, Jackowski M, Szeliga J. Laparoscopic surgery of esophageal hiatus hernia - single center experience. Videosurgery Miniinv 2014; 9: 13-7.

5. Kisielewski M, Rubinkiewicz $M$, Pedziwiatr $M$, et al. Are we ready for the ERAS protocol in colorectal surgery? Videosurgery Miniinv 2017; 12: 7-12.

6. Rubinkiewicz M, Witowski J, Su M, et al. Enhanced recovery after surgery (ERAS) programs for esophagectomy. J Thorac Dis 2019; 11: S685-91.

7. Mortensen K, Nilsson M, Slim K, et al. Consensus guidelines for enhanced recovery after gastrectomy. Br J Surg 2014; 101: 1209-29.

8. Halliday LJ, Markar SR, Doran SLF, Moorthy K. Enhanced recovery protocols after oesophagectomy. J Thorac Dis 2017; 9: S781-4.

9. Pędziwiatr M, Kisialeuski M, Wierdak M, et al. Early implementation of Enhanced Recovery After Surgery (ERAS $\left.{ }^{\circledR}\right)$ protocol compliance improves outcomes: a prospective cohort study. Int J Surg 2015; 21: 75-81. 
10. Jeong O, Park YK, Jung MR, Ryu SY. Compliance with guidelines of enhanced recovery after surgery in elderly patients undergoing gastrectomy. World J Surg 2017; 41: 1040-6.

11. Choi AH, Kim J, Chao J. Perioperative chemotherapy for resectable gastric cancer: MAGIC and beyond. World J Gastroenterol 2015; $21: 7343$.

12. Gustafsson UO, Oppelstrup H, Thorell A, et al. Adherence to the ERAS protocol is associated with 5-year survival after colorectal cancer surgery: a retrospective cohort study. World I Surg 2016; 40: 1741-7.

13. Pisarska M, Torbicz G, Gajewska N, et al. Compliance with the ERAS protocol and 3-year survival after laparoscopic surgery for non-metastatic colorectal cancer. World J Surg 2019; 43: 2552-60.

14. Smyth EC, Verheij M, Allum W, et al. Gastric cancer: ESMO Clinical Practice Guidelines for diagnosis, treatment and follow-up on behalf of the ESMO Guidelines Committee. Ann Oncol 2016; 27 (Suppl 5): v38-49.

15. Asklid D, Segelman J, Gedda C, et al. The impact of perioperative fluid therapy on short-term outcomes and 5-year survival among patients undergoing colorectal cancer surgery - a prospective cohort study within an ERAS protocol. Eur J Surg Oncol 2017; 43: 1433-9.

16. Gondal AB, Hsu CH, Serrot F, et al. Enhanced recovery in bariatric surgery: a study of short-term outcomes and compliance. Obes Surg 2019; 29: 492-8.

17. Fransen LFC, Luyer MDP. Effects of improving outcomes after esophagectomy on the short- and long-term: a review of literature. J Thorac Dis 2019; 11: S845-50.

18. Meillat H, Brun C, Zemmour C, et al. Laparoscopy is not enough: full ERAS compliance is the key to improvement of short-term outcomes after colectomy for cancer. Surg Endosc 2019. doi: 10.1007/s00464-019-06987-5.

19. Nowakowski M, Pisarska M, Rubinkiewicz M, et al. Postoperative complications are associated with worse survival after laparoscopic surgery for non-metastatic colorectal cancer - interim analysis of 3-year overall survival. Videosurgery Miniinv 2018; 13: 326-32.

20. Wang S, Xu L, Wang Q, et al. Postoperative complications and prognosis after radical gastrectomy for gastric cancer: a systematic review and meta-analysis of observational studies. World J Surg Oncol 2019; 17: 52.

21. Wells G, Shea B, O'Connell J, Robertson J, et al. The Newcastle-Ottawa Scale (NOS) for assessing the quality of nonrandomised studies in meta-analysis. 2011. http://www.ohri.ca/ programs/clinical_epidemiology/oxford.asp.

22. Li M, Wu W, Li L, et al. Is ERAS effective and safe in laparoscopic gastrectomy for gastric carcinoma? A meta-analysis. World J Surg Oncol 2018; 16: 17.

23. Carmichael JC, Keller DS, Baldini G, et al. Clinical practice guidelines for enhanced recovery after colon and rectal surgery from the American Society of Colon and Rectal Surgeons and Society of American Gastrointestinal and Endoscopic Surgeons. Dis CoIon Rectum 2017; 60: 761-84.

24. Gustafsson UO, Scott MJ, Hubner M, et al. Guidelines for perioperative care in elective colorectal surgery: Enhanced Recovery After Surgery (ERAS ${ }^{\circledR}$ ) Society Recommendations: 2018. World J Surg 2019; 43: 659-95.
25. Nygren J, Thacker J, Carli F, et al. Guidelines for perioperative care in elective rectal/pelvic surgery: Enhanced Recovery After Surgery (ERAS ${ }^{\circledR}$ ) Society recommendations. Clin Nutr 2012; 31: 801-16.

26. Pisarska M, Pędziwiatr M, Major P, et al. Laparoscopic gastrectomy with enhanced recovery after surgery protocol: single-center experience. Med Sci Monit 2017; 23: 1421-7.

27. Aarts MA, Rotstein OD, Pearsall EA, et al. Postoperative ERAS Interventions have the greatest impact on optimal recovery: experience with implementation of ERAS across multiple hospitals. Ann Surg 2018; 267: 992-7.

28. Kehlet H. ERAS implementation - time to move forward. Ann Surg 2018; 267: 998-9.

29. Chi F, Lan Y, Zhou S, et al. Learning curve of totally laparoscopic distal gastrectomy for gastric cancer: a single teaching hospital study. Videosurgery Miniinv 2018; 13: 442-7.

Received: 19.11.2019, accepted: 4.01.2020. 